\title{
What is the diplopia threshold?
}

\author{
A. L. DUWAER and G. VAN DEN BRINK \\ Department of Biological and Medical Physics, Erasmus University Rotterdam \\ 3000 DR Rotterdam, The Netherlands
}

\begin{abstract}
The magnitude and nature of the diplopia threshold, that is, the value of the retinal disparity at which binocular single vision ends, were studied in four experiments. The results show that the magnitude of the diplopia threshold is highly dependent on the subject tested (differences up to a factor of 6), the amount of training the subject has received (differences up to a factor of 2.5), the criterion used for diplopia (limits for unequivocal singleness of vision were up to a factor of 3 lower than those for unequivocal doubleness of vision), and the conspicuousness of disparity that can be influenced both by the surrounding stimuli (differences up to a factor of 3.5) and stereoscopic depth (differences up to a factor of 4.5). Our data do not confirm previous findings of interference effects associated with the initial appearance of binocular disparity when test stimuli are presented tachistoscopically. A remarkable finding was that the magnitude of the diplopia threshold seems to be determined by the amount of intrinsic noise in the disparity domain, as revealed by the standard deviations of the thresholds for tachistoscopically presented test stimuli. The overall results suggest that the diplopia threshold is, in essence, not the rigid boundary of a dead zone, but, rather, a disparity level corresponding to a lenient criterion for singleness of vision which leads to useful interpretation of the percept of the stimulus without disparity, given the variability of this percept due to intrinsic noise in the disparity domain.
\end{abstract}

An important aspect of human binocular vision is that a single visual percept can be obtained from two monocular images. This singleness of vision is accomplished by motoric alignment of the eyes so as to minimize the overall retinal disparity between the two monocular images and sensory integration of residual disparities. The sensory integration-usually called binocular fusion-can occur only when the residual retinal disparities between the two monocular images remain within certain limits.

Binocular fusion of parts of the images with horizontal disparity occurs practically without loss of disparity information, since only very small horizontal disparities $\left(\ll 1^{\prime}\right)^{\prime}$ do not give rise to a sensation of depth. Binocular fusion of image parts with vertical disparity, on the other hand, is usually assumed to result in a loss of disparity information, because no systematic perceptual change analogous to depth has yet been reported. ${ }^{2}$

This study is concerned with the diplopia threshold, that is, the largest value of the retinal disparity that does not disrupt binocular single vision.

Measured values of the diplopia threshold quoted in the literature have little or no utility, due to the

We would like to thank G. J. van der Wildt, A. E. H. Peters, and Ch. M. M. de Weert for helpful discussions, and C. J. Keemink and J. B. P. van Deursen for their technical assistance. This investigation was supported by the Netherlands Organization for the Advancement of Pure Research (ZWO). Requests for reprints may be sent to A. L. Duwaer, Department of Biological and Medical Physics, Erasmus University Rotterdam, P.O. Box 1738, 3000 DR Rotterdam, The Netherlands. enormous variation between the results reported by different authors. Reported diplopia thresholds have ranged from $2^{\prime}$ to $20^{\prime}$ for horizontal disparity in the fovea, from $3^{\prime}$ to $16^{\prime}$ for vertical disparity in the fovea, and from $1.4^{\circ}$ to $7^{\circ}$ for cyclodisparity (references will be given below). The situation is much the same for diplopia thresholds in the periphery of the visual field. For instance, at an eccentricity of $4^{\circ}-5^{\circ}$, diplopia thresholds from $4^{\prime}$ to $100^{\prime}$ have been reported (Crone \& Leuridan, 1973). Moreover, the smallest reported thresholds are so low that they can be accounted for by monocular acuity, so that it is not even necessary to assume the existence of binocular fusion (see, e.g., Kaufman \& Arditi, 1976a, 1976b). It is, therefore, of practical, as well as fundamental, importance to unravel the causes of this large variability in the size of the reported diplopia thresholds.

The purpose of the present investigation was to study the diplopia thresholds for vertical and horizontal disparity by evaluation of the criterion for binocular single vision. We also evaluated (1) possible interference effects associated with initial appearance of binocular disparity when test stimuli are presented tachistoscopically, (2) difference in the conspicuousness of information about the presence of disparity, and (3) possible systematic difference between subjects.

We have found evidence that different authors used different criteria for binocular single vision. In Woo's (1974) study, the criterion is likely to have been a perceptual change in the singleness of the line (e.g., broadening), as the reported diplopia thresholds $\left(1.8^{\prime}\right.$ 
$-2.0^{\prime}$ for a vertical line with horizontal disparity presented in the fovea for $100 \mathrm{msec}$ ) are not even large enough to compensate for the specified line width $\left(2.1^{\prime}\right)$. The same holds true for the small thresholds that can be inferred from the data of Kaufman and Arditi (1976b): $1.4^{\circ}-1.6^{\circ}$ cyclodisparity in horizontal lines $2^{\circ}$ long (corresponding to $1.5^{\prime}-1.8^{\prime}$ vertical disparity at $1^{\circ}$ eccentricity) is detectable $\left(\mathrm{d}^{\prime}=.61-2.11\right)$. Kaufman and Arditi determined the detectability of disparities, taking any changes in the appearance of the binocular image into account. On the other hand, when the transition from singleness to doubleness of vision is stressed for determination of the threshold, much larger diplopia thresholds are found (Mitchell, 1966: $6.8^{\prime}-11.5^{\prime}$ for horizontal disparity and $4.5^{\prime}$ 8.0' for vertical disparity; Crone \& Leuridan, 1973: $9^{\prime}-20^{\prime}$ for horizontal disparity and $5^{\prime}-16^{\prime}$ for vertical disparity, values estimated from the author's graphs; Sheedy \& Fry, 1979: $5^{\prime}-6^{\prime}$ for vertical disparity; Kertesz, 1973, and Kertesz \& Sullivan, 1976: $4^{\circ}-7^{\circ}$ cyclodisparity for horizontal lines $2^{\circ}$ long, which yields vertical disparities of $4.2^{\prime}-7.4^{\prime}$ at $1^{\circ}$ eccentricity). The data of Sheedy and Fry are interesting because they reveal shifts of the binocular images by $.25^{\prime}$ to $1.4^{\prime}$ (mean value $.8^{\prime}$ ) for a vertical disparity of $4^{\prime}$, which is less than their reported diplopia threshold. Since the mean $50 \%$ detection threshold for shifts under the particular stimulus condition amounted to about $.35^{\prime}$ (estimated from the specified mean width of the psychometric curves), Sheedy and Fry would have reported lower diplopia thresholds if they, like Kaufman and Arditi (1976b), had used detectability of disparity as the criterion for diplopia. For a proper interpretation of diplopia thresholds, it seems, therefore, necessary to discriminate carefully between at least two "thresholds": on the one hand, a threshold reflecting the ability to recognize a stimulus with retinal disparity (which we shall call the "singleness limit" from now on) and, on the other hand, the more commonly used threshold for the perception of two separate images (called the "doubleness threshold" below). Both thresholds were determined in our study.

Kertesz and Sullivan (1976) argued that diplopia thresholds for tachistoscopically presented disparities will be smaller than those for continuously presented disparities because of interference by the initial appearance of binocular disparity. This "initial appearance cue" is assumed to be caused by the slowness of binocular fusion, as a result of which the visibility of the disparity is not reduced immediately. If this is indeed the case, most recent data on the diplopia threshold will be affected by this cue, as nearly all recent work in this field has been done with tachistoscopically presented stimuli. We judged this question to be important enough to deserve investigation, and therefore determined the singleness limits and doubleness thresholds for both tachistoscopically and continuously presented test stimuli with disparity. In the case of continuously presented test stimuli, the disparity level was slowly changed, in order to avoid such transient effects as the initial appearance cue.

Kertesz and Sullivan (1976) also argued against the use of stimuli with conspicuous monocular cues about the presence of disparity, as used, for example, by Kaufman and Arditi (1976b). These conspicuous monocular cues are claimed to reduce the measured diplopia thresholds. We investigated this effect by using three different fixation markers giving monocular cues with different levels of conspicuousness.

\section{GENERAL METHODS}

\section{Stimulator}

The stimuli were presented in an electronic stereoscope consisting of a white background screen (diameter $15^{\circ}$, mean luminance level of $3 \mathrm{~cd} / \mathrm{m}^{2}$ ) and two XYZ displays (Philips PM3233 oscilloscopes with green P31 phosphor in Experiment 1 and HP1321 A displays with white P31 phosphor in Experiments 2, 3, and 4). The displays were viewed dichoptically through two beam splitters, positioned directly in front of the subject's eyes and adjusted so as to present the two displays in the same direction at a fixation distance of $105 \mathrm{~cm}$. The luminance of the (line) stimuli on the displays was adjusted to $1.8 \mathrm{log}$ units above the (contrast) threshold for the perception of the stimulus. The widths of the stimuli were $.3 \mathrm{~mm}\left(1.0^{\prime}\right)$ for the Philips display and $.35 \mathrm{~mm}\left(1.2^{\prime}\right)$ for the HP1321A display. ${ }^{3}$ The angular dimensions of the images on the two displays were equalized to within an accuracy of $.3^{\prime}$ when being looked at through a telescope (magnification 30). The parameter in the experiments was the disparity between certain parts of the stimuli on the display screens. The level of the disparity had an accuracy of $0.1^{\prime}$ and was controlled by a microprocessor and an 8-bit digital-to-analog convertor. The alignment and identity of the stimuli were checked with the telescope before and after each experimental session.

\section{Psychophysical Measuring Procedures}

Most of the results presented below were based on a "threealternative classification" of the test stimulus, but some data were gathered by a "two-alternative forced-choice" method. We shall now describe these two approaches in turn.

Three-Alternative Classification (see Figure 1)

Our three-alternative classification is an extension of the twoalternative classification, widely used in this field, in which the

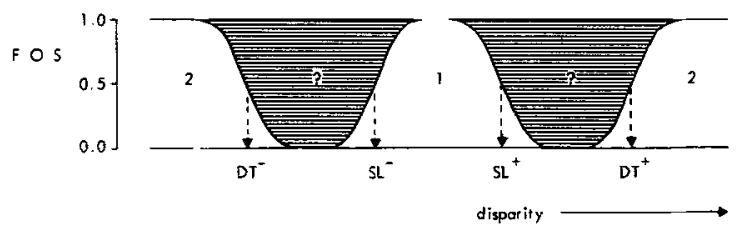

Figure 1. Schematic representation of the frequency of seeing (FOS) unequivocal singleness (1) and unequivocal doubleness (2) as a function of the disparity level in a classification procedure with neither unequivocal singleness nor unequivocal doubleness as the third alternative (?). 
subject is only allowed to answer "single" or "double." We found that these categories were not adequate because of the occurrence of transitional percepts between singleness and doubleness.

Our first alternative, "(1)," was an unequivocal single image which was defined as the "internal representation of the percept of the stimulus without disparity" (a sharp line, not broadened, not "restless," and perceived by both eyes). This internal representation was built up by familiarizing the subject with the percept of the stimulus without disparity. The second alternative, "(2)," was an unequivocal double image which was defined as the percept of two lines (with a separation). When the percept was neither unequivocally single nor unequivocally double, the subject was asked to select the third alternative, "(?)," and to describe the transitional percept afterwards. The disparity level above which an unequivocally single image is no longer seen determines the threshold for a perceived deviation from the internal representation of the percept of the stimulus without disparity. We shall refer to this threshold as the singleness limit (SL) from now on. The disparity level above which unequivocally double images are seen will be called the doubleness threshold (DT). The subjects were asked to classify in this way the percepts evoked by tachistoscopically presented test stimuli and by continuously visible test stimuli.

Tachistoscopic presentation. In the case of tachistoscopic presentation, the subject initiated presentation of the test stimulus by pressing a button. The stimulus was then presented with a constant disparity, selected at random by a microprocessor from 12 preselected values covering a sufficiently wide range to evoke all possible percepts. The subject then classified the percept. The subject was instructed to look at the fixation marker with close attention for at least 2-3 sec between successive stimulus presentations. In each session, the subject had to classify the percepts evoked by the 12 disparity values 20 times each. After that, the session was repeated at least once again with 12 interpolated disparity values, until a frequency-of-seeing (FOS) curve was obtained for each of the three image classes in which each transition from 0 to 1 was based either on at least four different points, each point based on at least 20 observations, or on the maximum number of points given the available resolution of $.33^{\prime}$.

Continuous presentation. The procedure was different for continuous observation of the test stimulus. Here each run was started by the subject with the aid of a switch. Two to $5 \mathrm{sec}$ later, the disparity slowly changed in steps of $.33^{\prime}, .66^{\prime}$, or $1.32^{\prime}$. The disparity started at a preselected positive value and then decreased through zero to a preselected negative value or increased through zero from negative to positive. The subject was asked to keep a button pressed as long as the percept of the stimulus fell into the intermediate category ("?," i.e., neither unequivocal singleness nor unequivocal doubleness). At the end of each run, the subject was to indicate (by pressing the appropriate button) whether his/her attention had been diverted or the fixation marker had not remained unequivocally single during the run. If so, the data were automatically excluded from the subsequent analysis. The subject continued until 20 good runs were completed. The direction of the change in disparity was then reversed, and another series was begun. The recordings were used to construct FOS curves for each of the three image classes.

Calculation of thresholds. The FOS curves obtained were fitted by a convolution of normalized Gaussian noise and hypothetical regions of disparity in which one of the three image classes is always seen. Each abrupt transiton between neighboring regions was defined to be a "threshold" with the standard deviation of the Gaussian noise as its standard deviation. This implies that the thresholds were calculated under the assumption that, at each disparity, one of the three percepts was always seen, but that the effective locations of the transitions between the percepts varied due to intrinsic additive Gaussian noise. All thresholds and standard deviations are means of the values found at positive and negative disparities. The data for continuous presentation of the test stimulus were also averaged over the values obtained with increasing and decreasing disparity.
Table 1

Details of the Subjects

\begin{tabular}{|c|c|c|c|c|c|c|c|}
\hline \multirow{2}{*}{$\begin{array}{l}\text { Sub- } \\
\text { ject }\end{array}$} & \multirow[b]{2}{*}{ Age } & \multirow[b]{2}{*}{ Sex } & \multicolumn{2}{|c|}{ Optical Correction } & \multicolumn{3}{|c|}{ Visual Acuity } \\
\hline & & & $\mathbf{L}$ & $\mathbf{R}$ & $\mathbf{L}$ & $\mathbf{R}$ & $S$ \\
\hline A.L.D. & 25 & M & S- .75 & .75 & $5 / 4$ & $5 / 4$ & $15^{n}$ \\
\hline C.J.K. & 38 & M & & & $5 / 4$ & $5 / 4$ & $30^{\prime \prime}$ \\
\hline B.D.L. & 32 & M & S-3.25 & S- 3.00 & $5 / 4$ & $5 / 4$ & $30 "$ \\
\hline A.E.H.P. & 25 & $\mathrm{~F}$ & $S-4.75^{*}$ & S- $4.75^{*}$ & $5 / 4$ & $5 / 4$ & $15^{\prime \prime}$ \\
\hline T.H.S. & 27 & M & S-7.00 & S- $7.00 *$ & $5 / 4$ & $5 / 4$ & $60^{\prime \prime}$ \\
\hline C.J.D. & 19 & $\mathbf{M}$ & $S-9.00$ & S-11.00 & $5 / 4$ & $5 / 4$ & $30^{\prime \prime}$ \\
\hline
\end{tabular}

Note $-L=$ left, $R=$ right, $S=$ stereo. Visual acuity was determined with the aid of the Landolt-C chart. Stereo acuity (in seconds) was tested with the TNO test based on random-dot patterns in anagliph form (Lameris, Utrecht, The Netheriands). Optical correction is expressed in diopters. *These subjects also viewed through an artificial pupil of diameter $2.5 \mathrm{~mm}$.

\section{Two-Alternative Forced Choice}

In this method, each trial was started by the subject's pressing a button. The test stimulus was then presented twice: first $.5 \mathrm{sec}$ after initiation and then $3 \mathrm{sec}$ after initiation. In one of the two presentation intervals, the test stimulus contained a disparity; in the other, it did not. The subject was asked to decide which interval contained the disparity. The correct answers for 50-100 trials were accumulated. At least three different disparity values were used to determine the disparity level producing $75 \%$ correct answers (which corresponds to a detection level of $50 \%$ ). This value will be called the "detection threshold." The detectionthreshold data presented below are means of the values obtained at positive and negative disparity.

\section{Experimental Procedure}

The subject was aligned in the test setup and provided (if necessary) with optical correction in order to achieve optimum sharpness of the perceived stimulus. The subject's head was fixed by using a bite-board. The luminance level of the stimuli on the screens was adjusted to $1.8 \mathrm{log}$ units above the threshold for perception of the stimulus. The subject was then informed of the experimental procedure described above, and was allowed ample time to look at the various stimuli and to familiarize him- or herself with the associated percepts. The experiments were then run as described in detail above. The subjects were asked to take a rest when they felt tired or when the sharpness of the perceived image deteriorated. The constancy of each subject's performance was monitored during collection of threshold data. When, by visual inspection of the FOS curves obtained, an apparent threshold shift was noticed, the preceding part of the experiment was repeated until no further shift was apparent. Threshold shifts occurred mainly during the first few experimental sessions for each subject.

\section{Subjects}

Six subjects participated in the various experiments (see Table 1). Only Subject A.L.D.- one of the authors-was aware of the purpose of the experiments. All but one had to be corrected optically to achieve optimum sharpness of the perceived stimulus. In order to obtain long-term stability for optimum sharpness, artificial pupils (diameter, $2.5 \mathrm{~mm}$ ) had to be used with two subjects (Subjects A.E.H.P. and T.H.S.).

\section{EXPERIMENT 1: THRESHOLDS FOR VERTICAL DISPARITY}

\section{Method}

\section{Stimuli}

The stimuli used in this experiment are depicted in Figure 2. They were presented in the middle of a white background screen, 


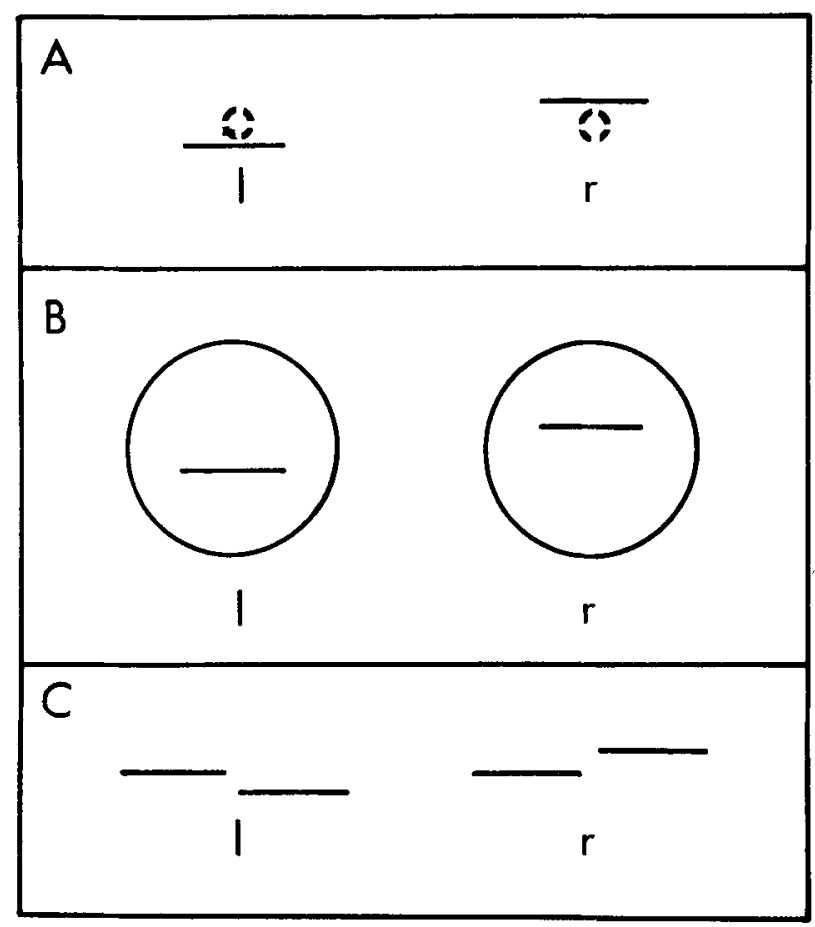

Figure 2. Schematic respresentation of the stimull used in Experiment 1. The letters $I$ and $r$ stand for presentation to the left and right eye, respectively. The broken line used to represent the $5^{\prime}$ fixation circle means that this marker disappears during the course of each trial before presentation of the stimulus.

on which the vertical orientation was marked by means of a black line (width $1.0^{\prime}$ ) with a gap $1.5^{\circ}$ wide in the middle, where the stimuli were presented. The stimuli on the display screen consisted of a fixation marker and a test stimulus.

Fixation markers. The fixation circle shown in Figure 2A, indicated by "[O]" from now on, had a diameter of 5'. The subjects were instructed to look at the middle of the circle, while waiting for the test stimulus. The circle disappeared $200 \mathrm{msec}$ before the test stimulus appeared and reappeared $.6 \mathrm{sec}$ after the test stimulus had vanished. This fixation marker can be regarded as giving highly inconspicuous cues concerning monocular displacements.

The fixation circle of Figure 2B (indicated by " $O$ ") had a diameter of $1^{\circ}$ and was continuously visible. With tachistoscopic presentation of the test stimulus, the subjects were instructed to look at the center of the circle. With continuous presentation of the test stimulus, the subjects were instructed to look alternately at the upper and lower halves of the circle, switching their gaze regularly to avoid fading of the test lines. This fixation marker may be regarded as giving monocular disparity cues of intermediate conspicuousness.

The left-hand line in Figure $2 \mathrm{C}$ was the third fixation marker (indicated by "-"). It was also continuously visible. It had a length of $30^{\prime}$ and was laterally separated from the test line by $3^{\prime}$. The subjects were instructed to look at the right-hand part of this marker, switching their gaze regularly from this part to the middle, when the test stimulus was continuously visible. This marker provides a highly conspicuous cue for monocular displacements.

Test stimulus. The test stimulus was a pair of dichoptic horizontal lines with a length of $30^{\prime}$, a width of $1.0^{\prime}$, and a variable vertical disparity.

When the test stimulus was presented tachistoscopically, the presentation time was $200 \mathrm{msec}$. (Such test stimuli are simply called " $200 \mathrm{msec}$ " from now on.) This presentation time is a compromise between allowing as much time as possible for fusion to develop, on the one hand, and preventing a raising of disparity thresholds by the interference of fusional eye movements, on the other. Experimentally, this raising was found not to occur for presentation times up to at least $200 \mathrm{msec}$. This agrees with data in the literature on reaction times of fusional eye movements. Fusional eye movements in the horizontal direction start after about $.2 \mathrm{sec}$ (Mitchell, 1970). A presentation time of about $200 \mathrm{msec}$ has the further advantage of providing a relatively familiar stimulus form: Large vertical foveal disparities are likely to be present for at least the reaction time of fusional eye movements in daily life.

When the test stimulus was presented continuously, the vertical disparity changed in steps of $.33^{\prime}$ at intervals of $800 \mathrm{msec}$, that is, at a rate of .4 '/ $\mathrm{sec}$ (such stimuli are called ". 4 ' $\mathrm{sec}^{-1 "}$ or ". $4 \mathrm{arc} \mathrm{min} / \mathrm{sec}$ "). The interference of fusional eye movements was minimized by foveal fixation of the marker. When fusional eye movements did, nevertheless, occur during the run, the subject could perceive this from the change that occurred in the appearance of the fixation marker, which did not remain single and usually became unequivocally double. Runs in which fusional eye movements were noticed were disregarded.

\section{Measuring Procedure}

The psychophysical measuring procedure used was threealternative classification.

\section{Results}

The disparity thresholds determined for the five subjects are presented in Table 2.

Table 2

Singleness Limits (SL) and Doubleness Thresholds (DT) With Their Standard Deviations (in Minutes of Arc) for Vertical Disparity in the Fovea

\begin{tabular}{|c|c|c|c|c|c|c|}
\hline \multirow{2}{*}{$\begin{array}{l}\text { Sub- } \\
\text { ject }\end{array}$} & \multirow[b]{2}{*}{$\mathrm{n}$} & \multicolumn{2}{|c|}{ SL } & \multirow[b]{2}{*}{$\mathrm{T}$} & \multicolumn{2}{|c|}{ DT } \\
\hline & & Mean & SD & & Mean & SD \\
\hline & \multicolumn{6}{|c|}{$[0], 200$ Msec } \\
\hline C.J.K. & 6 & 6.2 & 1.8 & 4 & 8.1 & 2.3 \\
\hline A.L.D. & 5 & 3.1 & 1.1 & 1 & 4.7 & .8 \\
\hline B.D.L. & 8 & 4.3 & .9 & 1 & 8.3 & 1.4 \\
\hline A.E.H.P. & 7 & 6.4 & 2.7 & 4 & 7.7 & 1.8 \\
\hline \multirow[t]{2}{*}{ T.H.S. } & 5 & 18.7 & 5.1 & $2 a$ & 29.8 & 7.7 \\
\hline & \multicolumn{6}{|c|}{$0,200 \mathrm{Msec}$} \\
\hline C.J.K. & 1 & 6.8 & 1.8 & $2 \mathrm{~b}$ & 8.4 & 2.1 \\
\hline & 3 & 5.7 & 2.5 & $2 b$ & 7.6 & \\
\hline A.L.D. & 1 & 2.5 & 1.0 & 1 & 4.5 & .8 \\
\hline D. & 6 & 2.4 & .8 & 1 & 4.1 & .8 \\
\hline \multirow{3}{*}{ B.D.L. } & 2 & 6.3 & 1.5 & 1 & 11.2 & 1.6 \\
\hline & 3 & 6.1 & 1.1 & 1 & 10.5 & 1.0 \\
\hline & 5 & 5.5 & 1.8 & 1 & 10.4 & 1.0 \\
\hline \multirow{3}{*}{ A.E.H.P. } & 1 & 7.4 & 7.3 & $2 \mathrm{a}$ & 20.0 & 3.0 \\
\hline & 5 & 5.0 & 4.8 & $2 a$ & 12.3 & 2.1 \\
\hline & 8 & 6.1 & 2.7 & 4 & 8.5 & 2.3 \\
\hline \multirow[t]{2}{*}{ T.H.S. } & 2 & 12.8 & 7.2 & $2 a$ & 25.8 & 4.4 \\
\hline & \multicolumn{6}{|c|}{,$- 200 \mathrm{Msec}$} \\
\hline C.J.K. & 4 & 4.2 & 2.5 & $2 \mathrm{~b}$ & 6.2 & 2.2 \\
\hline A.L.D. & 3 & 1.2 & .8 & 1 & 4.0 & 1.1 \\
\hline A.L.D. & 7 & 1.3 & .6 & 1 & 3.0 & .6 \\
\hline B.D.L. & 4 & 4.5 & 1.2 & 1 & 9.2 & 1.1 \\
\hline D.D.L. & 7 & 2.5 & 1.7 & 1 & 6.8 & 1.3 \\
\hline A.E.H.P. & 3 & 3.4 & 1.6 & $2 \mathrm{a}$ & 11.2 & 2.9 \\
\hline . R.L.H. & 9 & 3.7 & 1.8 & $2 a$ & 7.2 & 2.7 \\
\hline T.H.S. & 3 & 5.4 & 3.4 & $2 a$ & 19.8 & 3.4 \\
\hline
\end{tabular}


Table 2 (continued)

\begin{tabular}{|c|c|c|c|c|c|c|}
\hline \multirow{2}{*}{$\begin{array}{l}\text { Sub- } \\
\text { ject }\end{array}$} & \multirow[b]{2}{*}{$\mathbf{n}$} & \multicolumn{2}{|c|}{ SL } & \multirow[b]{2}{*}{$\mathrm{T}$} & \multicolumn{2}{|c|}{ DT } \\
\hline & & Mean & SD & & Mean & SD \\
\hline & \multicolumn{6}{|c|}{$0, .4 \mathrm{Arc} \mathrm{Min} / \mathrm{Sec}$} \\
\hline C.J.K. & 2 & 3.0 & .6 & $1 / 3^{*}$ & 6.5 & .8 \\
\hline A.L.D & 2 & 4.0 & .6 & 1 & 6.9 & .9 \\
\hline & 9 & 1.9 & .5 & 1 & 4.5 & .5 \\
\hline B.D.L. & 1 & 4.3 & .8 & 1 & 8.0 & .7 \\
\hline & 2 & 7.7 & 2.2 & 3 & 17.0 & 2.1 \\
\hline A.E.H.P. & 6 & 6.4 & 1.2 & 3 & 12.8 & 2.0 \\
\hline & 10 & 4.4 & 1.4 & 1 & 8.8 & 1.8 \\
\hline \multirow[t]{2}{*}{ T.H.S. } & 1 & 8.0 & 1.3 & $2 a / 3 \dagger$ & 17.0 & 3.3 \\
\hline & \multicolumn{6}{|c|}{,$- .4 \mathrm{Arc} \mathrm{Min} / \mathrm{Sec}$} \\
\hline C.J.K. & 5 & 2.8 & .7 & $1 / 3^{*}$ & 7.2 & 1.6 \\
\hline A.L.D. & 4 & 1.9 & .4 & 1 & 3.9 & .5 \\
\hline קום. & 8 & 1.2 & .3 & 1 & 3.5 & .5 \\
\hline B.D.L. & 6 & 3.1 & .6 & 1 & 7.0 & .6 \\
\hline A.E.H.P. & 4 & 4.0 & 1.4 & 3 & 12.0 & 2.5 \\
\hline 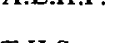 & 11 & 3.4 & 1.4 & 3 & 9.1 & 1.6 \\
\hline T.H.S. & 4 & 5.8 & 1.8 & $2 a / 3 \dagger$ & 17.9 & 2.8 \\
\hline
\end{tabular}

Note-T=transitional percept: (1) broadened, blurred, restless image; (2) displaced single image, (a) image of right eye, (b) image of left eye; (3) rivalry between the images in the left and right eyes; (4) subject not able to specify the transitional percept. $n=$ session number. $\quad$ Near $S L=1$; near $D T=3$. †For positive vertical disparity (image in right eye up, left eye down) and for negative disparities (right eye down, left eye up) near $S L=2 a$; for negative disparities near $D T=3$.

The singleness limits were found to vary between $1.2^{\prime}$ and $19^{\prime}$, and the doubleness thresholds between $3.0^{\prime}$ and $30^{\prime}$. Taken together, the range found is in good agreement with the overall range of diplopia thresholds reported by other authors (see the introduction).

The following, more detailed analysis is based upon the thresholds obtained in the last session of each experiment, when the subjects had reached stable performance. These thresholds are presented in Figgure $4 .{ }^{4}$ One of the subjects took a lot of experimental time to reach a stable performance. As shown in Figure 3, the thresholds decreased by up to $11.5^{\prime}$ (a factor of 2.3) from the start of the experiments to the end. The occurrence of this training effect has been both reported (see, e.g., Ogle, 1964) and denied (see, e.g., Mitchell, 1966) in the literature.

\section{Differences Between Subjects}

Inspection of Figure 4 reveals that differences between subjects are the most important cause of the large range of observed disparity thresholds.

It should be borne in mind that a large interindividual variability for a sensory threshold as such is not a surprising result, given the known interindividual variability of up to 1 order of magnitude for detection thresholds of, for example, the auditory system (Dadson \& King, 1952) and the vestibular system (Clark \& Stewart, 1969).

The interindividual variability is also reflected in the standard deviations of the thresholds. When the thresholds are expressed in standard-deviation units, the variability is reduced ${ }^{3}$ (see Figure 4). This implies that the interindividual relevance of this signal-tonoise ratio of the threshold is greater than that of the threshold itself. An important theoretical implication of this finding will be discussed below (see Summary and Conclusions of this section).

One of the possible factors underlying the enormous differences between the subjects seems to be the optical correction applied. In Figure 5, the disparity thresholds obtained in the first session of each experiment are compared with the optimum optical correction. Inspection of this figure shows that the initial threshold-especially the doubleness threshold-is higher when the optimum correction is larger. This can be made plausible in several ways.

One might argue that this dependency on optimum optical correction originates from the angular reduction of the retinal images that may occur in corrected myopes. This angular reduction does not occur when the need for optical correction is caused only by an elongated eye, but it does occur when the refractive power of the eye is too large (Ogle, 1971). Although we did not establish the nature of the myopias (so they might have had a refractive origin), we can still exclude angular reduction of the retinal images as the major cause of the higher thresholds at larger optimum optical corrections, because: (1) training may reduce the thresholds of subjects with large optimum optical corrections (see Figure 3); (2) the dependency on optimum correction should then be the same for all thresholds, which is not the case; and (3) the maximum effect of this angular reduction is comparatively small. A psychophysical experiment showed that a change of the effective refractive power of the eye by addition of a correction lens results in a perceived angular reduction of only $2.2 \%$ per diopter for the spectacles used. This implies that the actual disparity thresholds may be smaller by, at most, $0 \%$ for $0 \mathrm{~d}, 1.7 \%$ for $-.75 \mathrm{~d}, 6.9 \%$ for $-3.15 \mathrm{~d}, 10.5 \%$ for $-4.75 \mathrm{~d}$, and $15.4 \%$ for $-7 \mathrm{~d}$.

It is more likely that the dependency of the thresholds on the optimum optical correction reflects adaptation to vertical disparities in daily life as a result of small rotations in the frontal plane of an observer's spectacles.

Another cause of the interindividual variability of disparity thresholds, may be systematic differences in the accuracy of the alignment of the eyes. Our study on this was reported in Duwaer and van den Brink (Note 1).

\section{The Criterion for Diplopia}

The geometric means of the singleness limits are a factor of 1.5 to 2.6 less than the geometric means of the doubleness thresholds.

The differences are especially large for continuous presentation of the test stimulus and for tachistoscopic presentation in combination with the fixation line. A 


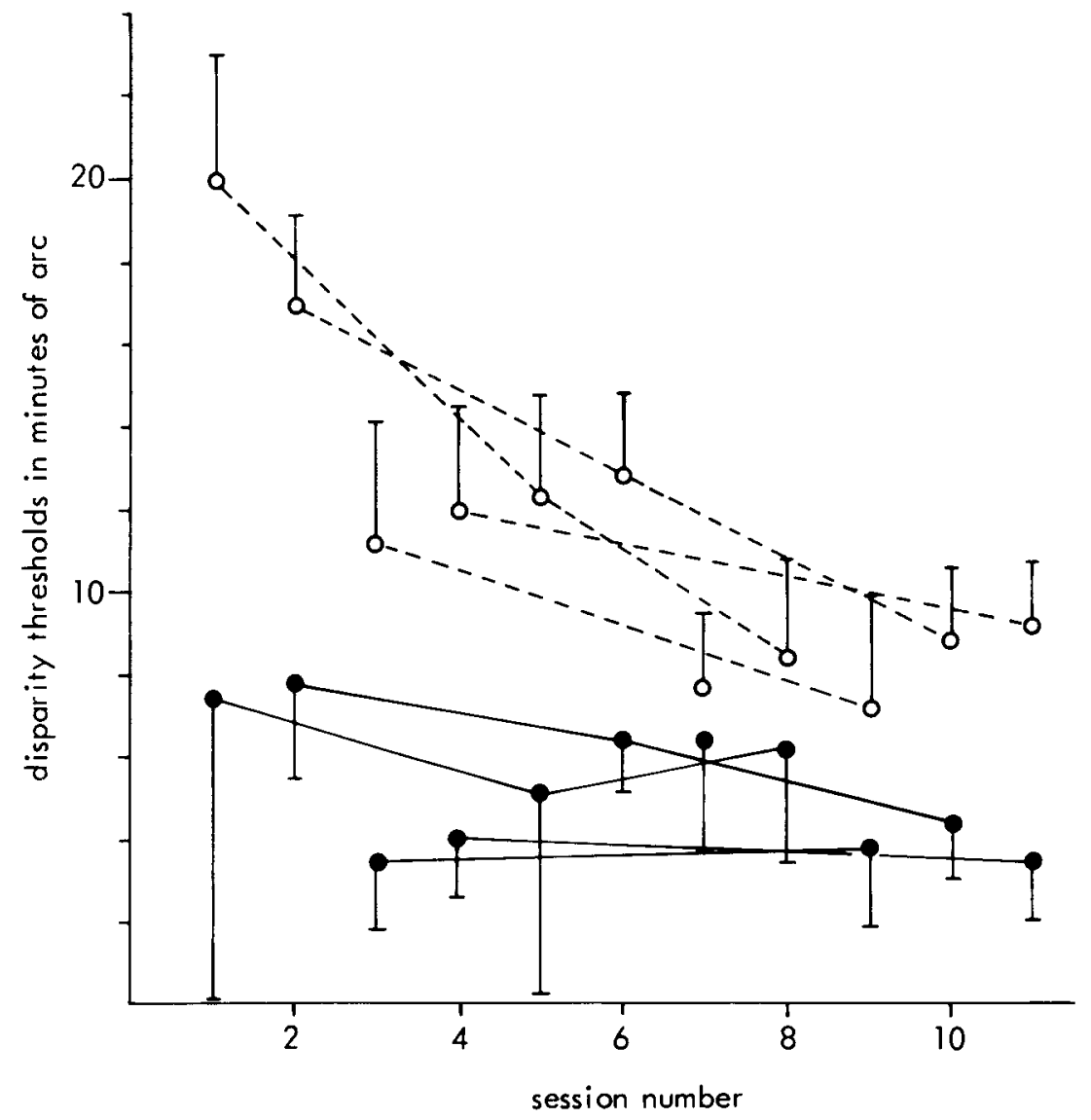

Figure 3. Disparity thresholds as a function of session number for Subject A.E.H.P. The singleness limits are represented by solid circles, and the doubleness thresholds, by open circles. The lines connect disparity thresholds determined under the same stimulus conditions, as given in Table 2. The lengths of the vertical bars are equal to the standard deviations.

discrimination between singleness limit and doubleness threshold would thus be at least of practical utility apart from any theoretical light it might throw on these matters.

All transitional percepts between unequivocal singleness and unequivocal doubleness seem to indicate partial elimination of disparity information by partial fusion or suppression (see Table 2). This implies that binocular single vision starts to deteriorate at the singleness limits, that is, well below the doubleness threshold.

\section{Conspicuousness of the Disparity}

When the test stimulus is presented in combination with the fixation line providing a highly conspicuous monocular displacement cue, the observed singleness limits fall. The same effect, but less marked, is found for the doubleness thresholds, but only when the test stimulus is presented tachistoscopically.

A major cause of this effect is a sharpening of the diplopia criterion. This can be seen from the fact that the signal-to-noise ratios also decrease when the fixation line, rather than one of the fixation circles (see Figure 4), is used.

It should be noted that the effect of the fixation line on the disparity thresholds need not necessarily be due to increased conspicuousness of the monocular displacements as such. It can also be caused by increased conspicuousness of the disparity due to greater variation of the disparity per unit of visual angle (higher disparity gradient). It should be borne in mind that a high disparity gradient with unnoticeable monocular displacements can be realized with the aid of random-dot stereograms.

\section{The Initial Appearance Cue}

Transient effects, such as an initial appearance cue, that may occur with tachistoscopically presented stimuli are avoided when the test stimulus is continuously visible and the disparity is slowly changing. In spite of the lack of this initial appearance cue, we found that the disparity thresholds do not rise, but actually tend to fall when the test stimulus is presented continuously. The relevance of the initial 

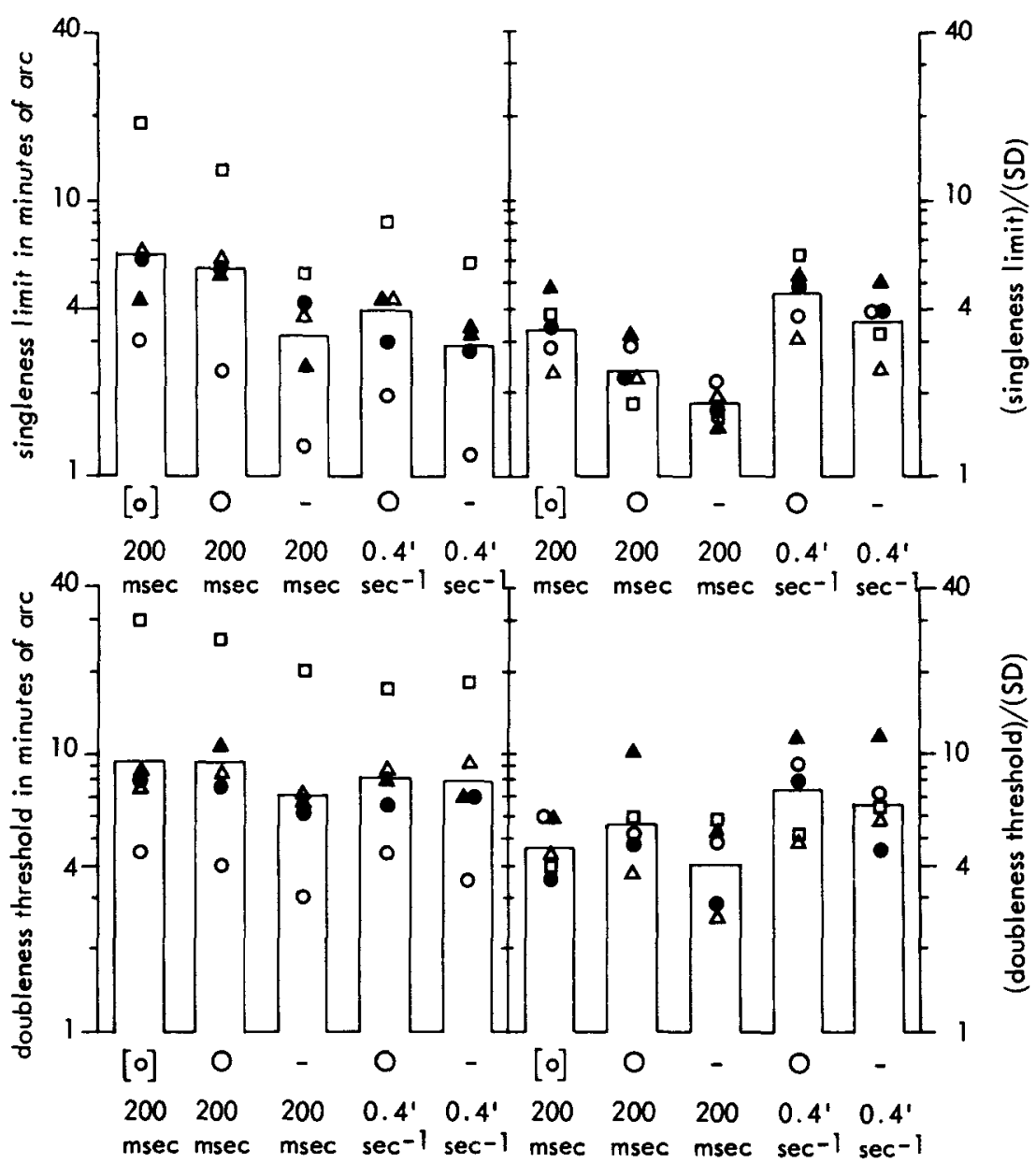

Figure 4. Disparity thresholds in minutes of arc (left part of the figure) and in standarddeviation units (right part of the figure) for the five different stimulus conditions. The thresholds in the upper part of the figure are the singleness limits. The doubleness thresholds are plotted in the lower part of the figure. Each type of symbol represents one of the five subjects. The height of the bars indicates the geometric mean of the thresholds.

appearance of binocular vertical disparity in tachistoscopically presented test stimuli may, therefore, be doubted. This conclusion is in agreement with that of Arditi and Kaufman (1978), who prevented interference effects due to an initial appearance cue by gradually increasing the intensity of their tachistoscopically presented test stimuli from below the perception limit.

\section{Summary and Conclusions}

The accuracy with which a disparity threshold can be determined, that is, its standard deviation, seems to have an important bearing on whether or not singleness of binocular vision is achieved.

The standard deviations obtained with tachistoscopic presentation of test stimuli of constant disparity can be interpreted as reflecting standard deviations of intrinsic noise in the disparity domain, because the internal representations of test stimuli of different disparities are built up independently. This is not the case for continuous presentation of test stimuli with a slow increase or decrease in disparity. Comparison of these standard deviations with the corresponding thresholds suggests that a diplopia threshold is set by a criterion that depends on the amount of intrinsic noise in the disparity domain.

Subjects tend to use a lenient criterion for the singleness limit, most probably because the disparity information is not very conspicuous. However, the criterion used becomes sharper when the disparity information is made more conspicuous.

Binocular single vision starts to deteriorate at a disparity level (the singleness limit) that may be much lower than the level where this deterioration is completed (i.e., the doubleness threshold) and unequivocal binocular double vision is established. 


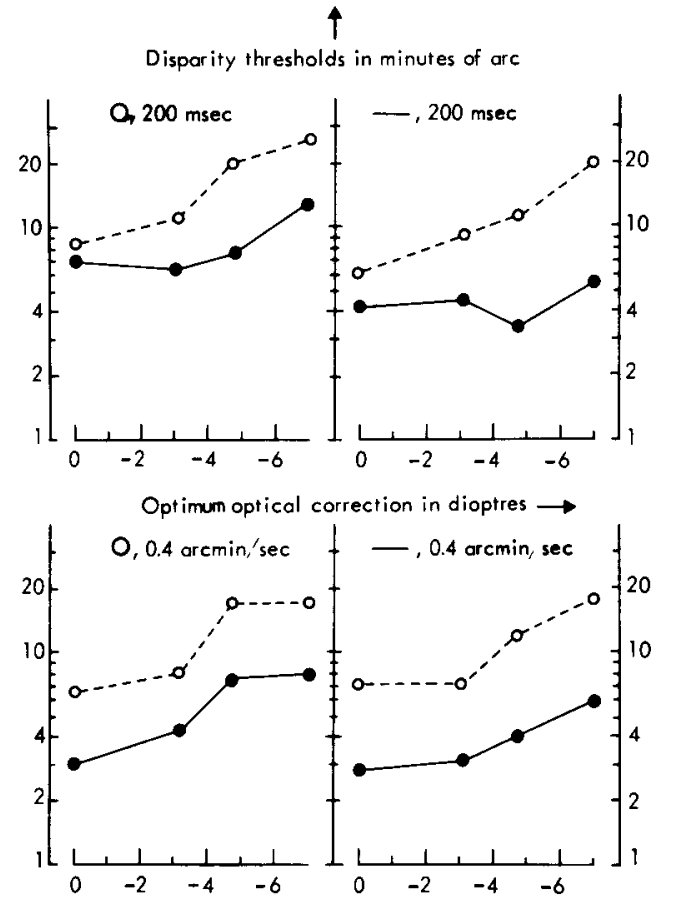

Figure 5. Singleness limits (solid circles) and doubleness thresholds (open circles) as functions of the optimum optical correction. The thresholds were determined in the first seasion performed under the particular stimulus conditions for each subject. The data for Subject A.L.D. (spherical correction of -.75 diopter) are omitted because his first sessions were preceded by a long period of observing foveal vertical disparity in a large number of pilot experiments.

It seems doubtful whether the initial appearance of binocular vertical disparity for tachistoscopically presented test stimuli lowers the diplopia threshold.

\section{EXPERIMENT 2: THRESHOLDS FOR VERTICAL DISPARITY OUTSIDE THE FOVEA}

In order to test the apparent importance of intrinsic noise in the disparity domain, we now compared thresholds for vertical disparity in the fovea with those outside the fovea, where this noise will be substantially larger.

\section{Method}

\section{Stimuli}

The stimuli consisted of a fixation marker, a test stimulus (both $1.8 \mathrm{log}$ units above the perception threshold) and a white background $\left(15^{\circ} \times 15^{\circ}\right.$; mean luminance level $\left.3 \mathrm{~cd} / \mathrm{m}^{2}\right)$.

Fixation marker. All fixation markers used consisted of three concentric squares of side $1^{\circ}, 1.2^{\circ}$, or $1.4^{\circ}$ and a vertical or horizontal line $10^{\circ}$ long (see Figure 6). For the determination of foveal thresholds, a gap was left in the central $1.4^{\circ}$ of the line. For the determination of thresholds outside the fovea, a line 20 long perpendicular to the longer line was added in the center to form a fixation cross.
During the determination of thresholds for horizontal test lines with vertical disparity, each subject was instructed to fix his gaze on the middle of the fixation marker, in the case of tachistoscopic presentation, and alternately on the upper and lower sides of the smallest square, in the case of continuous presentation. The fixation position had to be varied in the case of continuous presentation in order to prevent fading of the test lines.

Test stimulus. The test stimuli were presented at the center of the fixation marker (Figure 6a) $4.5^{\circ}$ to the right of the center (Figure $6 \mathrm{~b}$ ), or $4.5^{\circ}$ above the center (Figure $6 \mathrm{c}$ ).

The foveal test stimulus was $30^{\prime}$ long, and the peripheral test stimulus, $110^{\prime}$ long. According to the data of Drasdo (1977), these lines will stimulate about the same "length" in the visual cortex.

The test stimuli were presented either tachistoscopically, with a presentation time of $160 \mathrm{msec}$, or continuously while the disparity slowly changed at a rate of $.4^{\prime} / \mathrm{sec}$ in the fovea or $.8^{\prime} / \mathrm{sec}$ at an eccentricity of $4.5^{\circ}$.

\section{Measuring Procedure}

The psychophysical measuring procedure used was threealternative classification.

\section{Results}

Experiment 2 was performed by two subjects with a large difference in optimum optical corrections. Both subjects found it much less obvious to classify the percept evoked by the tachistoscopically presented test stimuli as "single" in the periphery of the visual field than in the fovea. Singleness, as such, had no meaning in the visual periphery, since the percept was only rarely perceived as single according to foveal standards. The classification "unequivocal single" should therefore not be interpreted too literally. It simply meant "perception of the stimulus without

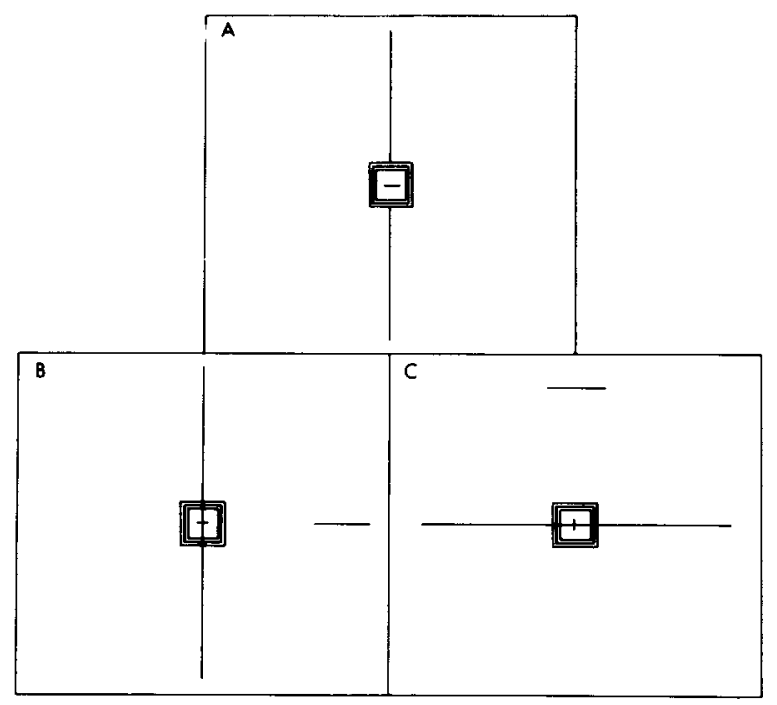

Figure 6. Schematic representation of the stimuli in Experiments 2 and 3 . The test stimulus was the horizontal line in the middle of the squares in $A$, to the right of the squares in $B$, and above the squares in $\mathbf{C}$. The remaining part of each stimulus served as a fixation marker. For Experiment 4 , the stimuli in $A$ and $C$ were rotated clockwise through $90^{\circ}$, and the stimulus in B, counterclockwise through $90^{\circ}$. 
disparity." Subject A.L.D. noticed that when the test stimulus was presented tachistoscopically without disparity, the percept varied between single and double according to the foveal standards. ${ }^{6}$ Being a highly skilled observer, Subject A.L.D. was able to apply the criteria "very good single," "single" (i.e., the ensemble of percepts evoked by the stimulus without disparity), and "not unequivocally double" consistently. The FOS curves obtained with the aid of these criteria are given in Figure 7A. When these curves are fitted by a convolution of normalized Gaussian noise and a range of disparities in which the percept in question is always seen, a remarkable result emerges. The limits of the above-mentioned ranges, the "thresholds," can vary between $3^{\prime}$ and $16^{\prime}$, while the accuracy with which these limits are determined changes much less (see Figure 7B). What is important here is this accuracy, that is, the amount of noise in the disparity domain. The classification "single" and "unequivocal double" are just two possible criteria on an apparently continuous scale. It also becomes evident why the singleness limit is roughly equal to twice its standard deviation. This standard deviation should be interpreted as reflecting the intrinsic noise in the disparity domain. As a result of this noise, a stimulus without disparity will result in an internal representation with an effective disparity of up to about 2-3 times the standard deviation of the noise. Apparently, the subjects "choose" their criterion for unequivocal singleness at this disparity level.

The data also indicate that binocular singleness or doubleness is determined by absolute retinal disparities and not by relative disparities in the stimulus. This may be concluded from the finding that optimum singleness (the center of the region of unequivocal singleness) was located at the nonzero stimulus disparities $\left(+12^{\prime}\right.$ for Subject C.J.D. and $-4^{\prime}$ for Subject A.L.D.) that compensated as well as possible the retinal disparities introduced by the cyclophorias of $2.5^{\circ}$ extorsion in Subject C.J.D. and $.8^{\circ}$ intorsion in Subject A.L.D. ${ }^{7}$ Because of the cyclophoria in Subject C.J.D., the effective disparity level of the
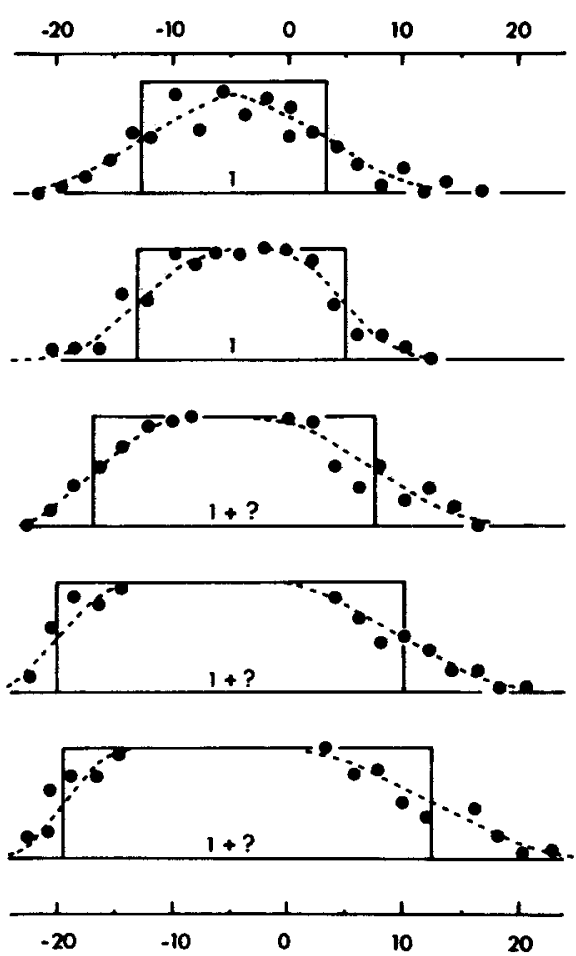

FOS

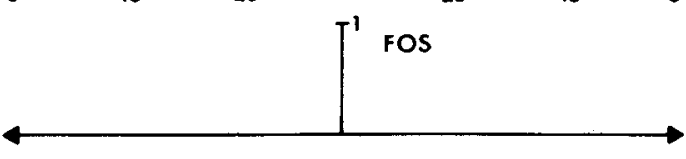

VERTICAL DISPARITY IN MINUTES OF ARC

Figure 7A. Frequencies of seeing "very good single" images (" 0 ," four sessions), "single" images (" 1 ," i.e., the ensemble of percepts evoked by the stimulus without retinal disparity, three sessions), and "not unequivocally double" images (" $1+$ ?," three sessions), represented by solid circles, as functions of the vertical disparity in a tachistoscopically presented horizontal line located $4.5^{\circ}$ to the right of the fixation point. These data were obtained for Subject A.L.D. Each experimental point was obtained from 20 trials. The asymmetries in the frequencies of seeing curves are caused by the cyclophoria in this subject (see text). 


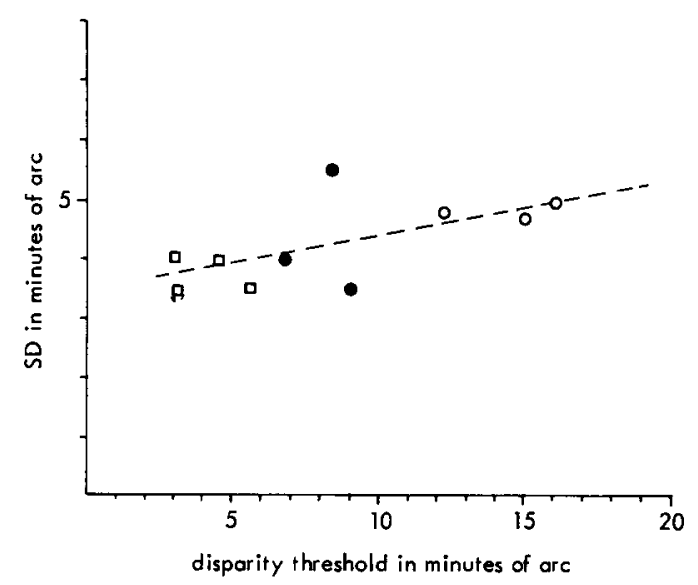

Figure 7B. The mean standard deviation of each "threshold" (the mean standard deviation of the distributions used to fit the experimental points in Figure 7A) are plotted as a function of the disparity threshold. The open squares represent "very good single" images, the solid circles, "single" images, and the open circles, "not unequivocally double" images. The dotted line is obtained by linear regression, with the standard deviation as dependent variable.

stimulus without disparity fell only just within the singleness limits!

The singleness limits and doubleness thresholds obtained are presented in Table 3.

At an eccentricity of $4.5^{\circ}$, the thresholds obtained vary between $6^{\prime}$ and $30^{\prime}$. This is appreciably less than the range reported in the literature, which extends up to $60^{\prime}$ (Crone \& Leuridan, 1973). Our major finding is that, just as in the fovea, the signal-tonoise ratios of the singleness limits for tachistoscopic presentation of the test stimulus amount to about 2 . The finding of a relatively constant signal-to-noise ratio for thresholds of different sizes thus seems to apply not only interindividually, but also intraindividually at different eccentricities.

\section{Conclusions}

The results of Experiment 2 confirm, and even reinforce, the importance of the amount of intrinsic noise in the disparity domain for the size of diplopia thresholds. It is, furthermore, evident that the singleness limits and doubleness thresholds are based on just two criteria on a continuous scale of possible criteria which even extends below the singleness limit.

The results also suggest that the singleness/doubleness disparity thresholds are determined by absolute retinal disparities and not by relative disparities in the stimulus as is, for example, the case for the detection threshold for horizontal disparity when detection is based on relative stereoscopic depth.

\section{EXPERIMENT 3: DETECTABILITY OF VERTICAL DISPARITY}

If even the singleness limit can be regarded as simply the result of applying a lenient criterion on a continuous scale of possible criteria, the detection threshold determined in a discrimination task that invites the subject to use the sharpest possible criterion should be below the singleness limit. ${ }^{8}$ This was checked in Experiment 3.

\section{Method}

Stimuli

The stimuli were the same as those used as in Experiment 2. The test stimulus was only presented tachistoscopically, with a presentation time of $160 \mathrm{msec}$. The reference stimulus contained no retinal vertical disparity.

\section{Measuring Procedure}

The psychophysical measuring procedure used was twoalternative forced choice.

\section{Results}

Experiment 3 was performed with the same two subjects used in Experiment 2. The results are given in Table 4.

Inspection of Tables 3 and 4 shows that all detection thresholds are, indeed, smaller than the corresponding singleness limits. The most remarkable performance was that of Subject C.J.D., who was found to be capable of detecting a foveal vertical disparity of only $2.2^{\prime}$, although his singleness limit amounted to $7.0^{\prime}$ and his diplopia threshold to as much as $19^{\prime}$, under the same stimulus conditions. This subject reported that he discriminated between the stimuli on the basis of minor differences in unequivocally single images. These differences between successive presentations were smaller than the variation of the percept evoked by the test stimulus without disparity in a large number of successive presen-

Table 3

Singleness Limits (SL) and Doubleness Thresholds (DT) With Their Standard Deviations (in Minutes of Arc) for Vertical Disparity in the Fovea, $4.5^{\circ}$ to the Right of the Fixation Point (4.5/0) and 4.5 Above the Fixation Point (4.5/90)

\begin{tabular}{|c|c|c|c|c|c|c|c|c|c|c|c|c|c|c|c|c|c|c|c|c|c|c|c|c|}
\hline \multirow{4}{*}{$\begin{array}{l}\text { Sub- } \\
\text { ject }\end{array}$} & \multicolumn{8}{|c|}{ Fovea } & \multicolumn{8}{|c|}{$4.5 / 0$} & \multicolumn{8}{|c|}{$4.5 / 90$} \\
\hline & \multicolumn{4}{|c|}{$160 \mathrm{Msec}$} & \multicolumn{4}{|c|}{$.4 \mathrm{Arc} \mathrm{Min} / \mathrm{Sec}$} & \multicolumn{4}{|c|}{$160 \mathrm{Msec}$} & \multicolumn{4}{|c|}{$.8 \mathrm{Arc} \mathrm{Min} / \mathrm{Sec}$} & \multicolumn{4}{|c|}{$160 \mathrm{Msec}$} & \multicolumn{4}{|c|}{$.8 \mathrm{Arc} \mathrm{Min} / \mathrm{Sec}$} \\
\hline & \multicolumn{2}{|c|}{ SL } & \multicolumn{2}{|c|}{ DT } & \multicolumn{2}{|c|}{ SL } & \multicolumn{2}{|c|}{ DT } & \multicolumn{2}{|c|}{ SL } & \multicolumn{2}{|c|}{ DT } & \multicolumn{2}{|c|}{ SL } & \multicolumn{2}{|c|}{ DT } & \multicolumn{2}{|c|}{ SL } & \multicolumn{2}{|c|}{ DT } & \multicolumn{2}{|c|}{ SL } & \multicolumn{2}{|c|}{ DT } \\
\hline & $\mathbf{M}$ & SD & $\mathbf{M}$ & SD & $\mathbf{M}$ & SD & $\mathbf{M}$ & SD & $\mathbf{M}$ & SD & $\mathbf{M}$ & SD & $\mathbf{M}$ & SD & $\mathbf{M}$ & SD & $\mathbf{M}$ & SD & $\mathbf{M}$ & SD & $\mathbf{M}$ & SD & $\mathbf{M}$ & SD \\
\hline $\begin{array}{l}\text { A.L.D. } \\
\text { C.J.D. }\end{array}$ & $\begin{array}{l}2.0 \\
7.0\end{array}$ & $\begin{array}{r}.7 \\
4.4\end{array}$ & $\begin{array}{r}3.6 \\
19.3 \\
\end{array}$ & $\begin{array}{r}.8 \\
2.5 \\
\end{array}$ & $\begin{array}{l}1.6 \\
3.6\end{array}$ & $\begin{array}{r}.5 \\
1.3 \\
\end{array}$ & $\begin{array}{r}4.7 \\
13.0 \\
\end{array}$ & $\begin{array}{r}.6 \\
2.0\end{array}$ & $\begin{array}{r}8.1 \\
16.9\end{array}$ & $\begin{array}{l}4.4 \\
7.7\end{array}$ & $\begin{array}{l}14.4 \\
29.3\end{array}$ & $\begin{array}{l}4.8 \\
6.4\end{array}$ & $\begin{array}{l}6.3 \\
9.6\end{array}$ & $\begin{array}{l}1.5 \\
3.9\end{array}$ & $\begin{array}{l}16.2 \\
19.7\end{array}$ & $\begin{array}{l}1.4 \\
3.8\end{array}$ & $\begin{array}{l}10.1 \\
19.0\end{array}$ & $\begin{array}{l}5.1 \\
7.8\end{array}$ & $\begin{array}{l}22.9 \\
27.6\end{array}$ & $\begin{array}{l}5.0 \\
4.8\end{array}$ & $\begin{array}{r}6.5 \\
14.0\end{array}$ & $\begin{array}{l}2.0 \\
3.0\end{array}$ & $\begin{array}{l}18.4 \\
23.6\end{array}$ & $\begin{array}{l}2.4 \\
3.2\end{array}$ \\
\hline
\end{tabular}


Table 4

Detection Thresholds (in Minutes of Arc) for Vertical Disparity in the Foven, $4.5^{\circ}$ to the Right of the Fixation Point (4.5/0), and 4.5 Above the Fixation Point (4.5/90)

\begin{tabular}{cccr} 
& \multicolumn{3}{c}{$160 \mathrm{Msec}$} \\
\cline { 3 - 4 } Subject & Fovea & $4.5 / 0$ & $4.5 / 90$ \\
\hline A.L.D. & 1.6 & 5.3 & 6.1 \\
C.J.D. & 2.2 & 14.1 & 14.5 \\
\hline
\end{tabular}

tations, which had not been noticed until this test procedure was applied. It should be noted that the difference between Subjects A.L.D. and C.J.D. became negligible in this experiment as far as the detectability of foveal disparity was concerned. However, their impression of the stimulus just above the detection threshold differed substantially: Subject A.L.D. certainly did not perceive an unequivocal single line; instead, he saw a restless, blurred, broadened line. It is not unlikely that this difference is due to the higher intrinsic noise level in Subject C.J.D., as a result of which he may have been more accustomed to the occurrence of these intermediate disparities.

In analyzing the magnitude of the detection thresholds found for vertical disparities, it must be reminded that these thresholds have a lower limit determined by the amount of intrinsic noise in the disparity domain. This lower limit is equal to $.955 \times$ the standard deviation of the intrinsic noise for the case of ideal signal detection without any loss of disparity information. Since both positive and negative vertical disparities result in a separation (without sign) of the test lines, it is not unlikely that information about the sign of the disparity is lost. Such a loss of sign information would raise the lower limit of the detection threshold to $1.49 \times$ the standard deviation of the intrinsic noise. Comparison of the measured detection thresholds with lower limits predicted on the basis of the standard deviations of the singleness limit and doubleness threshold as estimates of the standard deviation of the intrinsic noise suggests that it is necessary to assume some loss of disparity information to explain these results. In the highly practiced subject, A.L.D., this loss of information can be almost entirely ascribed to loss of information about the sign of disparities (in itself, quite a likely effect). This makes it tempting to deny the existence of any insurmountable loss of information about the magnitude of vertical disparities, that is, the occurrence of dead zones or of irreducible Panum's fusional areas for vertical disparities.

\section{Conclusion}

The detection threshold for vertical disparity (determined by a two-alternative forced-choice pro- cedure) is lower than the singleness limit and, of course, than the doubleness threshold (both determined by the three-alternative classification procedure above). This implies that neither the singleness limit nor the doubleness threshold can be interpreted as the boundary of a region of disparities in which the information about the size of disparity is lost. This agrees with similar results obtained by Kaufman and Arditi (1976b) for stimuli with cyclodisparity.

\section{EXPERIMENT 4: THRESHOLDS FOR HORIZONTAL DISPARITY}

In a final experiment, we gathered some data on the magnitude of thresholds for horizontal disparity.

\section{Method}

\section{Stimuli}

The stimuli were the same as those of Experiment 2, except that they were rotated through $90^{\circ}$ in the frontal plane (Figures 6A and 6C: clockwise rotation; Figure 6B: counterclockwise rotation). The foveal thresholds were determined while the subjects looked at the middle of the lower side of the smallest square in the case of tachistoscopic presentation and alternately at the left and right end of this side in the case of continuous presentation. The thresholds outside the fovea were determined while the subject fixed his gaze on the center of the fixation marker in the case of tachistoscopic presentation and alternately on the left and right sides of the smallest square in the case of continuous presentation. The fixation position had to be varied in the case of continuous presentation in order to prevent fading of the test lines.

\section{Measuring Procedure}

The psychophysical measuring procedures used were both threealternative classification and two-alternative forced choice.

\section{Results}

Experiment 4 was performed with two subjects, both of whom were found to base the detection threshold for horizontal disparity on the perception of relative depth in an otherwise unequivocal single image. ${ }^{9}$ These detection thresholds were much lower than those for vertical disparity. They amounted to $.2^{\prime}-.3^{\prime}$ in the fovea and to $.8^{\prime}-1.0^{\prime}$ at an eccentricity of $4.5^{\circ}$. These values are comparable to those obtained by other authors (e.g., Ogle, 1964).

When the horizontal disparity is further increased, the relative depth increases and, in addition, the appearance of the "single" percept, apart from its depth, changes. Both subjects characterized this change as a gradual increase in "glow," that is, diffuse irradiance, around the line. At an eccentricity of $4.5^{\circ}$, the line with glow eventually changes into one restless object of indeterminate appearance at an intermediate lateral position and with depth. At still larger disparities, the line becomes unequivocally double while the impression of depth strongly deteriorates. These descriptions are similar to those given by Ogle (1964), if Ogle's 
"fused line" is interpreted as a line without a substantial amount of "glow."

For determination of the singleness limits and doubleness thresholds, the subjects were instructed to disregard the complicating occurrence of depth and to concentrate on the appearance of the line perpendicular to the line of sight. The results are presented in Table 5.

The foveal disparity thresholds vary between 4 ' and $22^{\prime} .{ }^{10}$ This covers a substantial part of the range of values reported in the literature (see the introduction). The same can be said of the thresholds at an eccentricity of $4.5^{\circ}$, for which values between $13^{\prime}$ and $135^{\prime}$ were obtained. The differences between the two subjects become smaller when the thresholds are expressed in standard-deviation units and when the test line is continuously visible while the disparity slowly changes.

\section{Conclusions}

For horizontal disparities, disparity thresholds can be obtained that can vary by up to two orders of magnitude (in the fovea: $.25^{\prime}-22.2^{\prime}$; at an eccentricity of $\left.4.5^{\circ}, 1^{\prime}-135^{\prime}\right)$. The detection thresholds found here are markedly lower than those for vertical disparity. The singleness limits and doubleness thresholds, on the other hand, are higher than those for vertical disparity. The latter is not surprising, since, because of the accompanying occurrence of stereoscopic depth, deviations from singleness as a result of horizontal disparity are much less conspicuous.

\section{DISCUSSION}

\section{Which Threshold is the Diplopia Threshold?}

The singleness limits and doubleness thresholds, especially in the fovea, occur at disparity levels at which the interpretation of the binocular percept in terms of singleness and doubleness undergoes its two major changes. The singleness limit specifies the disparity level at which the perceived singleness of the stimulus starts to deteriorate, and the doubleness threshold marks the disparity level at which this deterioration is completed. The singleness limit and the doubleness threshold should thus be regarded as lower and upper limits of "the" diplopia threshold.
Although the detection thresholds are of major theoretical importance in the evaluation of the nature of the diplopia threshold, they have little or no utility as diplopia thresholds. The detection threshold for horizontal disparity is not at all useful as a diplopia threshold, because it is based on differences in depth in otherwise unequivocal single images, although there is evidence that this depth cue differs essentially from the singleness doubleness cue: Depth is based on a processing of relative disparities in the stimulus (disparity gradients; Duwaer \& van den Brink, Note 1), whereas the results of our Experiment 2 suggest that the singleness/doubleness cue is determined by absolute retinal disparities. The detection threshold for vertical disparity-though most probably based on a cue that does not differ essentially from the singleness/doubleness cue- is not so useful as a practical diplopia threshold because it specifies the performance of disparity detection in a discrimination task that is optimum for this purpose without considering the singleness of binocular vision as such.

\section{What Determines the Magnitude of the Diplopia Threshold?}

Our results suggest that an important determinant of the magnitude of the diplopia threshold is the amount of intrinsic noise in the disparity domain. When there is more noise, for example, outside the fovea or in some other subject, the diplopia threshold is higher.

The magnitude of the diplopia threshold also depends on the conspicuousness of changes in singleness due to the disparity. When these changes are made more conspicuous, for example, by the use of a fixation marker to make monocular displacements much more noticeable or with the aid of large disparity gradients, the diplopia thresholds reduce. ${ }^{11} \mathrm{On}$ the other hand, when the changes in singleness due to disparity are less conspicuous, for example, as a result of the absence of conspicuous monocular displacements or the occurrence of stereoscopic relative depth, the diplopia thresholds are higher.

The magnitude of the diplopia threshold was finally found to depend on the amount of training received by the subject and on systematic differences between subjects, in particular the optimum optical correction applied.

Table 5

Singleness Limits (SL) and Doubleness Thresholds (DT) With Their Standard Deviations (in Minutes of Arc) for Horizontal Disparity in the Fovea, $4.5^{\circ}$ to the Right of the Fixation Point (4.5/0) and 4.5 Above the Fixation Point (4.5/90)

\begin{tabular}{|c|c|c|c|c|c|c|c|c|c|c|c|c|c|c|c|c|c|c|c|c|c|c|c|c|}
\hline \multirow{4}{*}{$\begin{array}{l}\text { Sub- } \\
\text { ject }\end{array}$} & \multicolumn{8}{|c|}{ Fovea } & \multicolumn{8}{|c|}{$4.5 / 0$} & \multicolumn{8}{|c|}{$4.5 / 90$} \\
\hline & \multicolumn{4}{|c|}{$160 \mathrm{Msec}$} & \multicolumn{4}{|c|}{$.4 \mathrm{Arc} \mathrm{Min} / \mathrm{Sec}$} & \multicolumn{4}{|c|}{$160 \mathrm{Msec}$} & \multicolumn{4}{|c|}{ 1.6 $\mathrm{Arc} \mathrm{Min} / \mathrm{Sec}$} & \multicolumn{4}{|c|}{$160 \mathrm{Msec}$} & \multicolumn{4}{|c|}{ 1.6 $\mathrm{Arc} \mathrm{Min} / \mathrm{Sec}$} \\
\hline & \multicolumn{2}{|c|}{ SL } & \multicolumn{2}{|c|}{ DT } & \multicolumn{2}{|c|}{$\mathrm{SL}$} & \multicolumn{2}{|c|}{ DT } & \multicolumn{2}{|c|}{ SL } & \multicolumn{2}{|c|}{$\mathrm{DT}$} & \multicolumn{2}{|c|}{ SL } & \multicolumn{2}{|c|}{ DT } & \multicolumn{2}{|c|}{ SL } & \multicolumn{2}{|c|}{ DT } & \multicolumn{2}{|c|}{ SL } & \multicolumn{2}{|c|}{ DT } \\
\hline & $\mathbf{M}$ & SD & $\mathbf{M}$ & SD & $\mathbf{M}$ & SD & $\mathbf{M}$ & SD & $\mathbf{M}$ & SD & $\mathbf{M}$ & SD & $\mathbf{M}$ & SD & $\mathbf{M}$ & SD & $\mathbf{M}$ & SD & M & SD & M & SD & $\mathbf{M}$ & SD \\
\hline $\begin{array}{l}\text { A.L.D. } \\
\text { C.J.D. }\end{array}$ & $\begin{array}{r}4.8 \\
14.3\end{array}$ & $\begin{array}{l}1.5 \\
4.7\end{array}$ & $\begin{array}{r}7.5 \\
22.2\end{array}$ & $\begin{array}{l}1.5 \\
3.6\end{array}$ & $\begin{array}{l}3.9 \\
6.0\end{array}$ & $\begin{array}{r}.7 \\
1.9\end{array}$ & $\begin{array}{r}7.7 \\
15.1\end{array}$ & $\begin{array}{r}.7 \\
1.9\end{array}$ & $\begin{array}{l}13.5 \\
58\end{array}$ & $\begin{array}{c}7.4 \\
25\end{array}$ & $\begin{array}{l}23.1 \\
135\end{array}$ & $\begin{array}{l}11.3 \\
28\end{array}$ & $\begin{array}{l}19.3 \\
18.4\end{array}$ & $\begin{array}{l}4.2 \\
7.3\end{array}$ & $\begin{array}{l}50.2 \\
32.2\end{array}$ & $\begin{array}{l}5.9 \\
5.8\end{array}$ & $\begin{array}{l}13.6 \\
38\end{array}$ & $\begin{array}{l}12.5 \\
15\end{array}$ & $\begin{array}{l}32.9 \\
53\end{array}$ & $\begin{array}{l}18.7 \\
15\end{array}$ & $\begin{array}{l}14.8 \\
20.1\end{array}$ & $\begin{array}{l}4.1 \\
5.5\end{array}$ & $\begin{array}{l}52.1 \\
43.5\end{array}$ & $\begin{array}{l}4.9 \\
6.6\end{array}$ \\
\hline
\end{tabular}


Our results show that there is no need to assume interference due to initial appearance of binocular disparity for tachistoscopically presented test stimuli on the magnitude of the diplopia threshold. This may be concluded from the fact that the diplopia thresholds obtained with a continuously presented test stimulus were not consistently higher than those obtained for a tachistoscopically presented test stimulus.

\section{What is the Diplopia Threshold?}

Our results strongly suggest that the diplopia threshold is, in essence, not the rigid boundary of a dead zone, but a disparity level corresponding to a lenient criterion for singleness which leads to a useful interpretation of the percept of the stimulus without disparity, given the variability of this percept, due to intrinsic noise in the disparity domain.

\section{What is Binocular Fusion?}

The occurrence of binocular single vision in spite of disparities is generally ascribed to a process called binocular fusion. Our data confirm the conclusion of Kaufman and Arditi (1976a, 1976b) that the word "fusion" should not be interpreted too literally. It should be seen as the combined occurrence of an accurate combination of monocular localizations resulting in either stereoscopic depth or an intermediate binocular localization (Sheedy \& Fry, 1979) and an inaccurate and inconspicuous representation of the part of the disparity information that encodes the appearance of the image, already accurately determined before binocular combination.

\section{REFERENCE NOTE}

1. Duwaer, A. L., \& Brink, G. van den. Foveal diplopia thresholds and fixation disparities. Submitted for publication, 1980.

\section{REFERENCES}

Arditi, A., \& Kaufman, L. Singleness of vision and the initial appearance of binocular disparity. Vision Research, 1978, 18, $117-120$.

Clark, B., \& Stewart, J. D. Effects of angular acceleration on man: Thresholds for the perception of rotation and the oculogyral illusion. Aerospace Medicine, 1969, 40, 952-956.

Crone, R. A., \& Leuridan, P. M. A. Tolerance for aniseikonia. I. Diplopia thresholds in the vertical and horizontal meridians of the visual field. II. Determination based on the amplitude of cyclofusion. Albrecht v. Graefes Archiv für Klinisches und Experimentelle Ophthalmologie, 1973, 188, 1-22.

Dadson, R. S., \& KInG, J. H. A determination of the normal threshold of hearing and its relation to the standardization of the audiometers. Journal of Laryngology and Otology, 1952, 66, 366-378.

Drasdo, $\mathbf{N}$. The neural representation of visual space. Nature, $1977,266,554-556$.

Kaufman, L., \& Arditi, A. Confusion prevails. Vision Research, $1976,16,551-552$. (a)

Kaufman, L., \& Arditi, A. The fusion illusion. Vision Research, 1976, 16, 535-543. (b)

Kertesz, A. E. Disparity detection within Panum's fusional areas. Vision Research, 1973, 13, 1537-1543.
Kertesz, A. E., \& Sullivan, M. J. Fusion prevails: A reply to Kaufman and Arditi. Vision Research, 1976, 16, 545-550.

Mitchell, D. E. Retinal disparity and diplopia. Vision Research, $1966,6,441-451$.

Mitchell, D. E. Properties of stimuli eliciting vergence eye movements and stereopsis. Vision Research, 1970, 10, 145-162.

OGLE, K. N. Researches in binocular vision. New York: Hafner, 1970.

OGLe, K. N. Optics. Springfield, Ill: Thomas, 1971.

Palmer, D. A. Measurement of the horizontal extent of Panum's area by a method of constant stimuli. Optica Acta, 1961, 8, 151-159.

SheEdy, J. E., \& Fry, G. A. The perceived direction of the binocular image. Vision Research, 1979, 19, $201-211$.

Woo, G. C. S. The effect of exposure time on the foveal size of Panum's area. Vision Research, 1974, 14, 473-480.

\section{NOTES}

1. In this paper, all retinal disparities and dimensions of perceived images are expressed in degrees of arc or minutes of arc, which, for the sake of simplicity, are denoted by, for example, " 5 " " or " 1 "," respectively.

2. With the exception of the "induced effect": In some subjects and under some stimulus conditions, stereoscopic depth can be induced by vertical magnification of one of a pair of monocular images (Ogle, 1964).

3. The line width was measured at a fixation distance of $10 \mathrm{~cm}$ by determining the separation between two lines giving rise to a just noticeable gap.

4. Analysis of variance shows that the difference between the geometric means of the singleness limits and the doubleness thresholds is significant $[F(1,4)>23, p<.01]$ for all stimulus conditions. The effect of the criterion on the geometric means of the signal-to-noise ratios is significant $(\mathrm{p}<.05)$ only for " $0,200 \mathrm{msec}$ " $[F(1,4)=28, p<.01]$, for ",- 200 msec" $[F(1,4)=16.5, p<.02]$, and for ",$- .4 \mathrm{arc} \mathrm{min} / \mathrm{sec} "[\mathrm{~F}(1,4)=21.7, \mathrm{p}<.01]$.

The singleness limits for the test line in combination with the fixation line are significantly lower than those for the test line in combination with the fixation circles $[F(1,4)>20, p<.01]$. The singleness limits expressed in standard-deviation units are lower for the test line in combination with the fixation line when the former is presented tachistoscopically $[F(1,4)>7.4, p<.05]$.

The doubleness thresholds for the tachistoscopically presented test line in combination with the fixation line are lower than those of the tachistoscopically presented test line in combination with the fixation circles $[F(1,4)>15, p<.02]$. The fixation marker does not have a significant effect on the doubleness thresholds expressed in standard-deviation units $[F(1,4)<5.5, p>.06]$.

The only significant effect of the presentation time on the size of the disparity thresholds occurs for the singleness limits in combination with the fixation circle $[F(1,4)=25, p<.01]$. The presentation time influences the magnitude of the singleness limits expressed in standard-deviation units for both fixation stimuli $[F(1,4)>$ $12, p<.02]$ and the magnitude of the doubleness thresholds expressed in standard-deviation units when the fixation line is used $[F(1,4)=14, p<.02]$.

5. Analysis of variance of the effect of the criterion and stimulus conditions on geometric means shows that differences between subjects are not a significant source of variance $[F(1,4)<7.7$, $p>.5]$ for the thresholds expressed in standard-deviation units, whereas these differences were significant $[F(1,4)>11, p \leq .02]$ for the absolute values of the thresholds.

6. This agrees with results obtained by Palmer (1961). He found that the frequency of seeing a single image does not always reach the value 1.0 for a stimulus without disparity in the visual periphery, which implies that even this stimulus must have been seen as double in part of the presentations.

7. These cyclophorias were discovered only after the investigation had been under way for some time. Their value was estimated 
with the aid of a pair of dichoptic horizontal lines, seen in diplopia.

8. See Appendix.

9. It is our finding that relative depth is not always seen under all stimulus conditions. If it is not seen, the percept at intermediate horizontal disparities is remarkably similar to that at intermediate vertical disparities.

10. When Subject A.L.D. looked at the upper part of a vertical fixation line that was $30^{\prime}$ long and positioned $3^{\prime}$ below a $30^{\prime}$-long vertical test line with horizontal disparity, the doubleness threshold even fell to $2.2^{\prime} \pm .8^{\prime}$ when the test line was presented tachistoscopically with a presentation time of $200 \mathrm{msec}$.

11. An important example of a dichoptic stimulus with highly noticeable monocular displacement is a stimulus with cyclodisparity, since the thresholds for the perception of tilt in monocular lines with cyclorotation are low compared with the corresponding diplopia thresholds (see, e.g, Kaufman \& Arditi, 1976b).

\section{APPENDIX}

\section{Threshold Considerations}

Different assumptions may be made concerning the processes underlying the diplopia threshold. The consequences of the various assumptions will be discussed.

1. If the disparity thresholds are "real" thresholds, that is, if they correspond to the boundary of a dead zone, which is wide in comparison with the intrinsic noise in the disparity domain, then the following relation exists between the detection threshold (obtained in a discrimination task), the singleness limit, and the doubleness threshold (both obtained in a three-alternative classification task):

$$
\begin{aligned}
\text { Detection threshold } & =\text { singleness limit } \\
& =\text { doubleness threshold. }
\end{aligned}
$$

This can be understood when it is remembered that all three thresholds here refer to the disparity that gives $50 \%$ frequency of seeing the disparity in the stimulus.

2. If, on the other hand, the disparity thresholds are not "real" thresholds but are determined with reference to criteria chosen from a continuous scale of possible criteria extending to zero disparity in a disparity domain with constant additive intrinsic noise, then the detection threshold will be determined by signal-detection considerations.

If no loss of disparity information may be expected during signal detection, the following is obtained:

$$
\begin{aligned}
\text { Detection threshold }= & .955 \times \text { standard deviation } \\
& \text { of singleness limit } \\
& =.955 \times \text { standard deviation } \\
& \text { of doubleness threshold. }
\end{aligned}
$$

Signal detection with loss of information about the sign of the disparity would result in:

$$
\begin{aligned}
\text { Detection threshold }= & 1.49 \times \text { standard deviation } \\
& \text { of singleness limit } \\
= & 1.49 \times \text { standard deviation } \\
& \text { of doubleness threshold. }
\end{aligned}
$$

These relations may be derived as follows: In the twoalternative forced-choice procedure, the subject is comparing the percepts of two stimuli presented in succession in order to determine which percept embodies a disparity. In the three-alternative classification, the subject is assessing the percept of each stimulus presented with reference to two criteria, that is, two disparity levels.

(a) Assume that the internal representation of the disparity in the test stimulus is increased with a sample of a normalized Gaussian distribution so that the density function of a large number of internal representations of the same stimulus disparity is:

$$
p(d)=\frac{1}{\sigma_{d} \sqrt{2 \pi}} \exp \left[\frac{-(d-d)^{2}}{2 \sigma_{d}^{2}}\right],
$$

where $d=$ disparity, $\delta=$ disparity in the test stimulus, and $\sigma_{\mathrm{d}}=$ standard deviation of the additive Gaussian noise.

(b) Assume that the internal representations of stimuli presented in succession are mutually independent.

Under these assumptions, the statistics of the decisions in the three-alternative classification procedure are governed by the distribution $\mathbf{p}(\mathrm{d})$. This implies that the standard deviation of the disparity thresholds obtained with this procedure is equal to $\sigma_{\mathrm{d}}$.

The frequency of correct discrimination, $P_{c}(\delta)$, in the two-alternative forced-choice situation when there is no loss of disparity information, is given by:

$$
P_{c}(d)=\int_{-\infty}^{+\infty} p_{s n}(d=x) P_{n}(d<x) \partial x,
$$

where $p_{s n}=$ the probability that the internal representation of the stimulus with disparity is located at disparity $\mathrm{x}$,

$$
\mathrm{p}_{\mathrm{sn}}=\frac{1}{\sigma_{\mathrm{d}} \sqrt{2 \pi}} \exp \left[\frac{-(\mathrm{x}-\delta)^{2}}{2 \sigma_{\mathrm{d}}{ }^{2}}\right]
$$

and $P_{n}(d<x)=$ the probability that the internal representation of the stimulus without disparity is located at a disparity that is smaller than $x$,

$$
P_{n}(d<x)=\int_{-\infty}^{x} \frac{1}{\sigma_{d} \sqrt{2 \pi}} \exp \left[\frac{-d^{2}}{2 \sigma_{d}^{2}}\right] \partial d
$$

The frequency of correct detection will be $50 \%$ for $P_{c}\left(d^{\prime}\right)$ $=.75$, which corresponds to $d^{\prime}=.955$.

The frequency of correct discrimination, $P_{c}^{\prime}(\delta)$, in the two-alternative forced-choice procedure when information about the sign of the disparity is lost is given by:

$\mathbf{P}_{c}^{\prime}(d)$

$$
=\int_{0}^{\infty}\left\{\left[\mathrm{p}_{\mathrm{sn}}(\mathrm{d}=+\mathrm{x})+\mathrm{p}_{\mathrm{sn}}(\mathrm{d}=-\mathrm{x})\right] \mathrm{P}_{\mathrm{n}}(-\mathrm{x}<\mathrm{d}<+\mathrm{x})\right\} \partial \mathrm{x},
$$

where $p_{s n}(d= \pm x)=$ the probability that the internal representation of the stimulus with disparity is located at disparity $\pm x$, 


$$
\mathrm{p}_{\mathrm{sn}}(\mathrm{d}= \pm \mathrm{x})=\frac{1}{\sigma_{\mathrm{d}} \sqrt{2 \pi}} \exp \left[\frac{-( \pm \mathrm{x}-\delta)^{2}}{2 \sigma_{\mathrm{d}}{ }^{2}}\right]
$$

$$
P_{n}(-x<d<+x)=\int_{-x}^{+x} \frac{1}{\sigma_{d} \sqrt{2 \pi}} \exp \left[\frac{-d^{2}}{2 \sigma_{d}^{2}}\right] \partial d
$$

and $P_{n}(-x<d<+x)=$ the probability that the internal representation of the stimulus without disparity is located between the disparities $-x$ and $+x$,

The frequency of correct detection will be $50 \%$ for $\mathrm{P}_{c}^{\prime}\left(\delta^{\prime \prime}\right)$ $=.75$, which corresponds to $\delta^{\prime \prime}=1.49 \sigma_{\mathrm{d}}$. 